\title{
Detection and Quantization of Bearing Fault in Direct Drive Wind Turbine via Comparative Analysis
}

\author{
Wei Teng, Rui Jiang, Xian Ding, Yibing Liu, and Zhiyong Ma \\ School of Energy, Power and Mechanical Engineering, North China Electric Power University, Beijing 102206, China \\ Correspondence should be addressed to Wei Teng; tengw@ncepu.edu.cn
}

Received 6 January 2016; Revised 7 March 2016; Accepted 3 April 2016

Academic Editor: Mohamed El Badaoui

Copyright (C) 2016 Wei Teng et al. This is an open access article distributed under the Creative Commons Attribution License, which permits unrestricted use, distribution, and reproduction in any medium, provided the original work is properly cited.

\begin{abstract}
Bearing fault is usually buried by intensive noise because of the low speed and heavy load in direct drive wind turbine (DDWT). Furthermore, varying wind speed and alternating loads make it difficult to quantize bearing fault feature that indicates the degree of deterioration. This paper presents the application of multiscale enveloping spectrogram (MuSEnS) and cepstrum to detect and quantize bearing fault in DDWT. MuSEnS can manifest fault modulation information adaptively based on the capacity of complex wavelet transform, which enables the weak bearing fault in DDWT to be detected. Cepstrum can calculate the average interval of periodic components in frequency domain and is suitable for quantizing bearing fault feature under varying operation conditions due to the logarithm weight on the power spectrum. Through comparing a faulty DDWT with a normal one, the bearing fault feature is evidenced and the quantization index is calculated, which show a good application prospect for condition monitoring and fault diagnosis in real DDWT.
\end{abstract}

\section{Introduction}

Wind energy has developed rapidly in the last decade, especially in China; the accumulated installed capacity has ranked at the top of the world since $2012[1,2]$. However, suffering from harsh operation environments such as varying wind speed, alternating loads, and extreme difference in temperature, wind turbine (WT) is prone to break down, which causes high maintenance cost and economic loss $[3,4]$. Large scale horizontal axis wind turbine can be categorized into gearboxdriven and direct drive machines based on the structure of the drive train [5]. In a gearbox-driven WT, a gearbox is adopted to transfer the mechanical energy from rotor hub with low rotational speed to double fed induction generator with high speed. Oppositely, in a direct drive wind turbine (DDWT), the rotor hub is coupled to permanent magnet synchronous generator directly, and a full-rated converter is used to transform varying mechanical speed to consistent frequency of power grid [6]. The removal of gearbox simplifies the structure of DDWT; however, heavy rotor system consisting of blades, rotor hub, and rotor of generator acts on the two supporting bearings installed on the main shaft, which causes bearings to be failure readily. Correspondingly, the faults such as air gap eccentricity, rubbing, and scrapping between stator and rotor of generator arise inevitably and may induce catastrophic results for DDWT. Therefore, we should pay more attention to detect and diagnose bearing fault in DDWT to improve the operational reliability.

The researches about bearing fault detection and diagnosis accumulated abundant achievements. McFadden and Smith $[7,8]$ developed single point and multiple point defects model of inner race of a rolling element bearing, which provided fundamental research for bearing fault detection. Afterwards, a variety of technologies and methods were applied to diagnose bearing fault with the development of the signal processing. Tandon and Choudhury [9] summarized the vibration and acoustic methods for the detection of bearing localized and distributed defects based on the analysis in time, frequency, and time-frequency domain. Bearing fault often excites resonance at certain natural frequency of the bearing components, which causes a phenomenon of resonance modulation. Enveloping demodulation combining narrow-band filtering is referred to as an effective tool to find the bearing fault features [10]. To overcome the disadvantage of the selection of narrow band manually, Antoni and Randall [11] proposed a method of spectral kurtosis, 
which can decompose signal into different frequency bands and regard the band with maximum kurtosis as the optimal filtering narrow band. To enhance the impact brought from bearing fault in vibration signals, autoregressive model and minimum entropy deconvolution were developed to restrain the periodic components of gear mesh and background noise $[12,13]$. Randall et al. [14] presented cepstrum prewhitening to remove deterministic components in cepstral domain, and Borghesani et al. [15] applied this method to diagnose bearing faults under variable speed conditions. Due to necessary random slips, possible speed fluctuations, and variations of the axial to radial load ratio, the vibration signal from real bearing fault was considered as cyclostationary, and cyclic spectral analysis was performed by Antoni to evidence a fault in high level of background noise [16]. Rai and Mohanty [17] diagnosed bearing fault using FFT and Hilbert-Huang transform based on the ability of nonstationary signal processing. Randall and Antoni [18] summarized some effective methods to detect incipient defect of bearing including linear prediction, adaptive noise cancellation, discrete separation, time synchronous averaging, and so forth.

Due to the large scale and heavy load of direct drive WT, the vibratory impact of bearing fault is usually weak and buried by intensive background noise. Moreover, low speed of rotor hub makes the fault feature frequency of bearing too small to be observed. For example, the bearing fundamental train frequency at rated rotational speed of DDWT is less than $0.2 \mathrm{~Hz}$, which is possible out of the linear measurement range of acceleration transducer. Therefore, it is difficult to extract and quantize bearing fault feature in DDWT. The minority studies referred to the fault diagnosis about DDWT, especially for bearing fault feature extraction and quantization under the operation condition of varying speed and alternating loads. An et al. [19] applied the ensemble empirical mode decomposition and Hilbert transform to analyze pedestal looseness of a DDWT; however, the study is based on small scale test rig which cannot represent the characteristic of real wind turbine.

In this paper, a comparative analysis of a faulty DDWT with a normal one is made to detect and quantize the bearing fault. Firstly, the structure of DDWT is described and its characteristic is analyzed. Then, the multiscale enveloping spectrogram (MuSEnS) that can decompose signal at different frequency bands and obtain multiscale envelope spectrum is introduced to evidence bearing fault feature frequency in the faulty DDWT. Next, a cepstrum based fault quantization index is proposed to represent the degree of bearing fault, which can exclude the influence of operation conditions. Finally, a summary is made to discuss the noteworthy matters in the real test for DDWT. The proposed methods show a good application prospect for condition monitoring and fault diagnosis in real DDWT.

\section{Direct Drive Wind Turbine}

2.1. Structure of Direct Drive Wind Turbine. External rotor with permanent magnets excited is the mainstream structure of the DDWT due to the high energy yield [20]. The structure

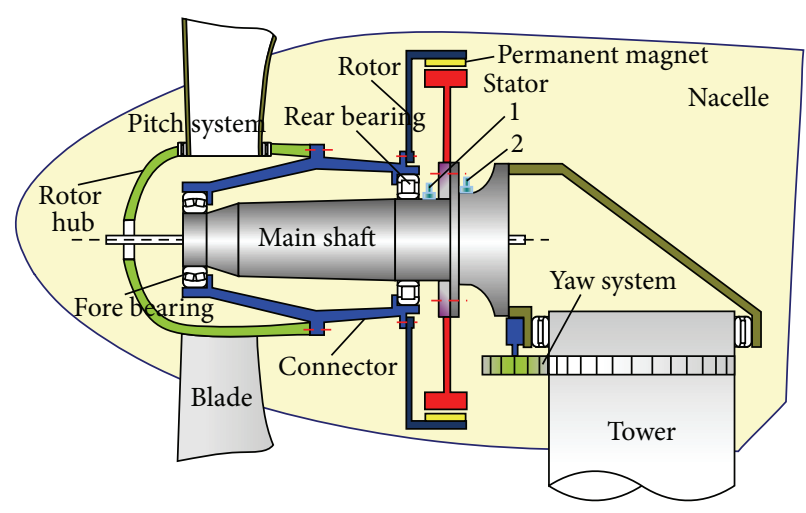

FIGURE 1: Structure of the direct drive wind turbine.

of DDWT is shown as in Figure 1. The external rotor of generator glued with permanent magnets, the connector, and the rotor hub form the rotor system that is driven by three blades. The pitch system connects the three blades to the rotor hub and adjusts absorbed wind energy through tuning the pitch angles. The stator system is comprised of the stator of generator with coils and the irrotational main shaft. The rotor system and stator system are installed on the tower in its entirety and covered by a nacelle. All the parts in nacelle rotate to face the wind via a yaw system.

The rated rotational speed of DDWT is much lower than double fed induction generator because of the absence of speed-up gearbox. Therefore, the number of pole pairs in direct drive generator should be enough to achieve a relatively high grid frequency $(50 \mathrm{~Hz}$ in China), which can enhance the weight and volume of the DDWT. In addition to the heavy rotor system of generator, the weight of the three blades and the stochastic impact of wind acting on bearings bring a challenge for safety operation of the bearings.

2.2. Bearing Fault Feature. The rotor system in this case is supported by two bearings, as shown in Figure 1, the fore bearing is double row tapered roller bearing, and the rear one is cylindrical roller bearing. The fault analysis is implemented for the rear bearing.

For cylindrical roller bearing, the roller pass frequency of inner race (RPFI), roller pass frequency of outer race (RPFO), and roller spin frequency (RSF) of rolling element can be calculated as

$$
\begin{aligned}
& f_{I}=\frac{f_{r} N_{b}}{2}\left(1+\frac{d}{D} \cos \varphi\right), \\
& f_{O}=\frac{f_{r} N_{b}}{2}\left(1-\frac{d}{D} \cos \varphi\right), \\
& f_{R}=\frac{f_{r} D}{2 d}\left(1-\left(\frac{d}{D} \cos \varphi\right)^{2}\right) .
\end{aligned}
$$

Due to the outer race rotation, the fundamental train frequency (FTF) can be shown as

$$
f_{F}=\frac{f_{r}}{2}\left(1+\frac{d}{D} \cos \varphi\right)
$$




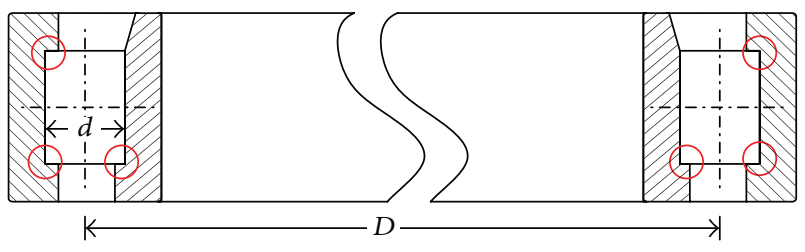

FIGURE 2: Structure of the cylindrical roller bearing.

where $f_{r}$ is the rotational frequency of the external rotor, $d$ is the roller diameter which is 40 millimeter, $D$ is the pitch diameter which is 791 millimeter, $N_{b}$ is the number of the cylinder rollers which is 49 , and $\varphi$ is the contact angle of bearing. The parameters of cylindrical roller bearing are shown in Figure 2.

In the rear bearing of the DDWT, as the rolling elements strike a local defect on the inner race or outer race, a shock is generated. As shown in Figure 3(a), while defect exists on inner race, the interval of vibration shock is the reciprocal of the RPFI and there is no modulation phenomenon because the inner race is stationary. When defect arises on outer race, the rollers strike the defective part on outer race which can introduce the shock with interval of the reciprocal of the RPFO. Meanwhile, the vibration shock is modulated by the rotational frequency of the external rotor, with the defective part on the outer race entering into the load zone (on the top) and leaving the load zone, shown as in Figure 3(b). Similarly in Figure 3(c), the vibration shock happens when a defect on a roller strikes either inner race or outer race and is modulated by the FTF, with the defective roller entering and leaving the load zone. The motion processes of external rotor bearing with outer race defect and roller defect are shown as in Figure 4.

\section{Multiscale Enveloping Spectrogram}

3.1. Comparison of Demodulation Methods. Demodulation analysis is an impactful tool to detect modulation information that represents fault component in bearing diagnosis. There are many demodulation methods applied to rotating machinery fault diagnosis, such as generalized detectionfiltering demodulation [21, 22], Hilbert transform [10], and cyclostationary demodulation [6, 23-25].

An integral arithmetic is adopted in Hilbert transform to convert signal to an imaginary part. Combining the signal itself as a real part, an analytic signal is generated whose module is the enveloping signal including modulation information. However, Hilbert demodulation analysis needs selecting certain frequency band including modulation information to filter original vibration signal. Since the selection of narrow-band range depends on human's experiences to a great extent, it may cause incorrect demodulation results.

Second-order cyclostationary (CS2) demodulation is effective to diagnose machinery fault because most of revolutions in gear or bearing system can be considered as cyclostationary process. It firstly converts autocorrelation of original signal to cyclic autocorrelation function (CACF) using Fourier transform in alpha domain. Then, CACF is converted to cyclic spectral density (CSD) using Fourier transform in frequency domain. Therefore, an original signal can be shown in a $f$ - $\alpha$ surface that evidences carrier and modulation components. However, modulation frequency and its harmonics still distribute on both sides of carrier frequency in $f-\alpha$ surface and cannot be separated alone, which may lead to identification difficulty especially; there are multifault sources.

Compared with the above demodulation methods, complex wavelet transform exhibits its excellent ability in demodulation analysis. It enables simultaneous filtering signals at different bandwidth and obtaining multiscale envelope spectrum (MuSEnS) based on the characteristic of complex wavelet transform. MuSEnS just reveals the modulation information ignoring the carrier components.

3.2. Definition of MuSEnS. Complex wavelet has the property of being analytic in nature and is defined as $[26,27]$

$$
\psi(t)=\psi_{R}(t)+j \psi_{I}(t)=\psi_{R}(t)+j H\left[\psi_{R}(t)\right],
$$

where $\psi_{R}(t)$ is the real part of complex wavelet, $\psi_{I}(t)$ is the imaginary part of the complex wavelet, and $\psi_{I}(t)$ is the Hilbert transform of $\psi_{R}(t)$, which is shown as

$$
\psi_{I}(t)=H\left[\psi_{R}(t)\right]=\int_{-\infty}^{\infty} \frac{\psi_{R}(\tau)}{\pi(t-\tau)} d \tau .
$$

Figure 5 shows the complex Morlet wavelet used in this paper.

The complex wavelet transform of $x(t)$ is

$$
w t_{C}(a, \tau)=w t_{R}(a, \tau)+j w t_{I}(a, \tau),
$$

where

$$
\begin{aligned}
& w t_{R}(a, \tau)=|a|^{-1 / 2} \int_{-\infty}^{\infty} x(t) \psi_{R}^{*}\left(\frac{t-\tau}{a}\right) d t, \\
& w t_{I}(a, \tau)=|a|^{-1 / 2} \int_{-\infty}^{\infty} x(t) H\left[\psi_{R}^{*}\left(\frac{t-\tau}{a}\right)\right] d t ;
\end{aligned}
$$

in (5) and (6), $a$ denotes the scale factor and $\tau$ denotes the shift factor.

The result after complex wavelet transform is analytic. From the modulus of the analytic result $w t_{C}(a, \tau)$, the envelope signal is derived as

$$
\begin{aligned}
e_{w t}(a, \tau) & =\left\|w t_{C}(a, \tau)\right\| \\
& =\sqrt{w t_{R}(a, \tau)^{2}+H\left[w t_{R}(a, \tau)\right]^{2}} .
\end{aligned}
$$

Therefore, the band-pass filtering and multiscale envelope analysis can be finished simultaneously. Further, using Fourier transform, MuSEnS can be calculated as

$$
\begin{aligned}
E_{w t}(a, f) & =F\left(e_{w t}(a, \tau)\right) \\
& =\frac{1}{2 \pi} \int_{-\infty}^{\infty}\left\|w t_{C}(a, \tau)\right\| e^{-j 2 \pi f \tau} d \tau .
\end{aligned}
$$




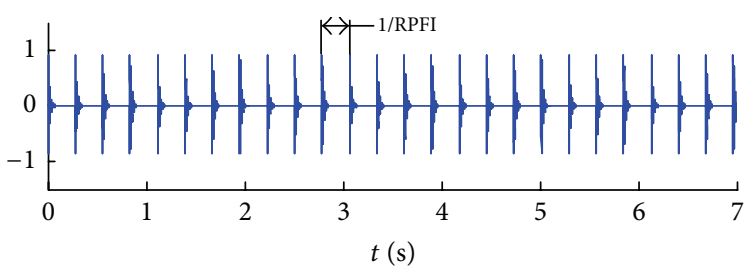

(a)

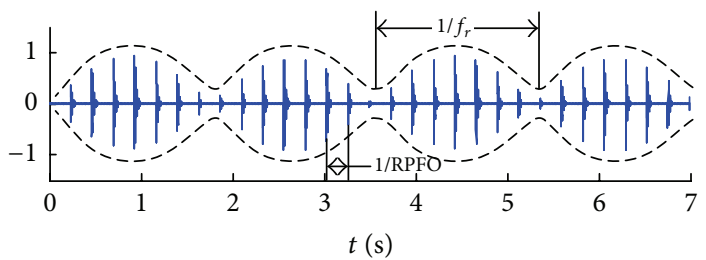

(b)

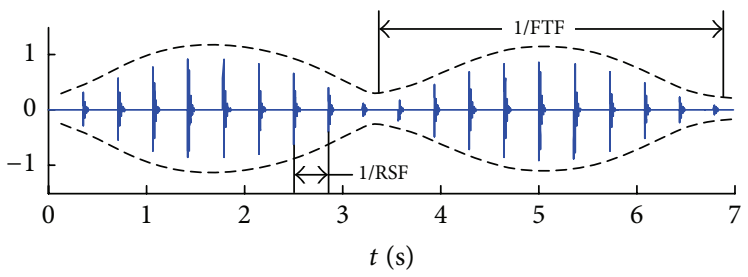

(c)

FIgURE 3: Bearing fault signals. (a) Inner race fault, (b) outer race fault, and (c) roller fault.

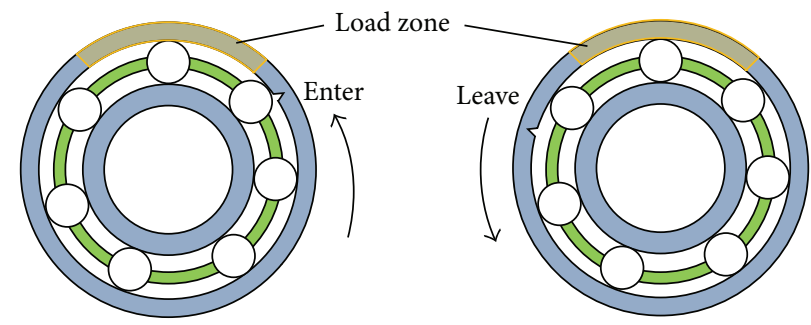

(a)

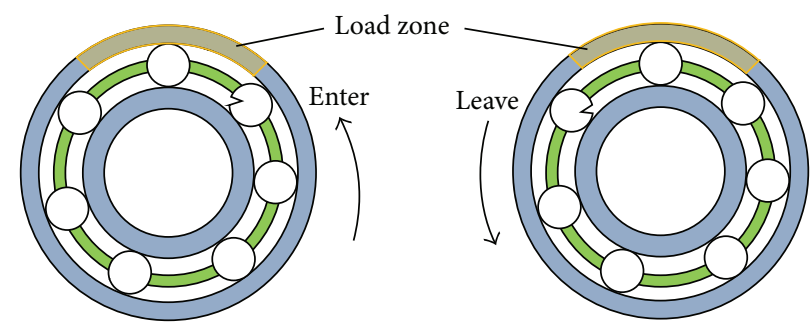

(b)

FIGURE 4: Motion processes of external rotor bearing with defect. (a) Outer race fault and (b) roller fault.

\section{Cepstrum Analysis}

4.1. Definition of Cepstrum. Spectral analysis can reveal the periodic components in time signal using Fourier transform. Correspondingly, the Fourier transform of spectrum can also reveal the periodic components in frequency domain. The cepstrum of signal was defined as the "power spectrum of the log power spectrum" originally [28]. Afterwards it was revised as the "inverse Fourier transform of the log power spectrum," which is defined as $[29,30]$

$$
\begin{aligned}
C_{x}(\tau) & =F^{-1}[\log |X(f)|] \\
& =\int_{-\infty}^{\infty}\left[\log \left|\int_{-\infty}^{\infty} x(t) e^{-j 2 \pi f t} d t\right|\right] e^{j 2 \pi f \tau} d f,
\end{aligned}
$$




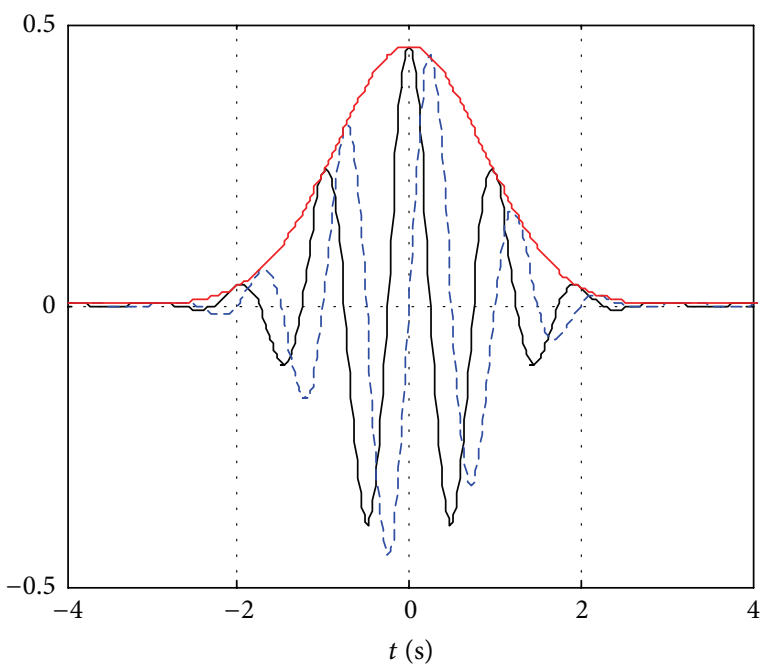

(a)

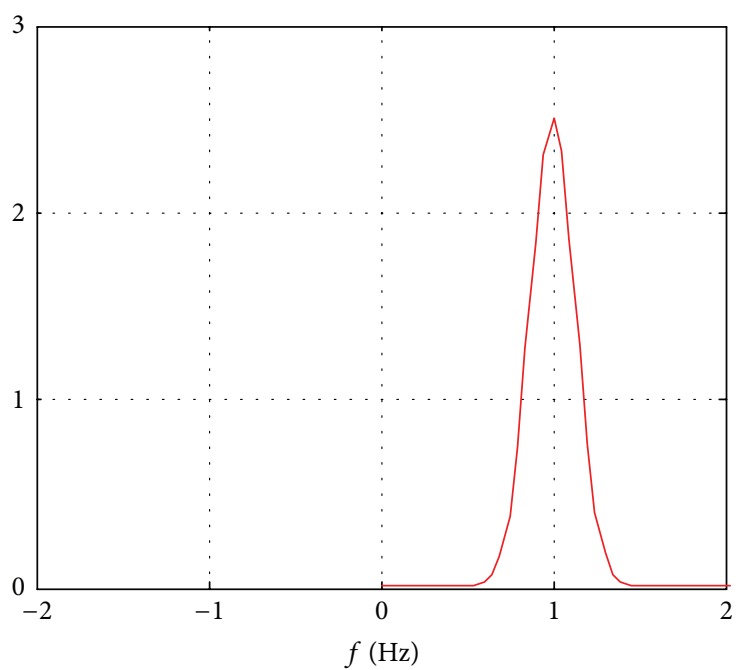

(b)

Figure 5: Complex Morlet wavelet. (a) Real part (black line), imaginary part (dash line), and envelope (red line); (b) FFT of the complex Morlet wavelet.

where $X(f)$ denotes the Fourier transform of $x(t), F^{-1}$ is an indicator of inverse Fourier transform, and $\tau$ is the quefrency.

The cepstrum calculates the average interval of multiple harmonics in frequency domain, and thus it can distinguish the neighbor frequency components accurately. And it has been recognized as a powerful tool to detect gear and bearing defect in industrial applications $[31,32]$.

4.2. Characteristic of the Cepstrum. The time signal $x(t)$ collected from vibration transducer is the convolution product of vibration source $s(t)$ itself and the impulse response function $h(t)$ of transmission path, which is described as

$$
x(t)=s(t) * h(t)=\int_{0}^{\infty} s(\tau) h(t-\tau) d \tau
$$

It is difficult to identify the vibration source and transmission path in time domain, so Fourier transform is applied for $x(t)$. According to the convolution theorem [33], the convolution product of $s(t)$ and $h(t)$ can be replaced by the multiplication of $S(f)$ and $H(f)$, which is shown as

$$
X(f)=S(f) \cdot H(f)
$$

where $X(f), S(f)$, and $H(f)$ are the Fourier transforms of $x(t), s(t)$, and $h(t)$ respectively. Further, the logarithm is applied as

$$
\log [X(f)]=\log [S(f)]+\log [H(f)] .
$$

Then, the inverse Fourier transform is used to process the logarithm result, which is shown as

$$
\begin{aligned}
F^{-1}\{\log [X(f)]\}= & F^{-1}\{\log [S(f)]\} \\
& +F^{-1}\{\log [H(f)]\} .
\end{aligned}
$$

Here, the convolution product of $s(t)$ and $h(t)$ in time domain is transformed in addition to cepstrum domain

$$
C_{x}(q)=C_{s}(q)+C_{h}(q)
$$

where $C_{x}(q), C_{s}(q)$, and $C_{h}(q)$ are the cepstrum of $x(t), s(t)$, and $h(t)$, respectively.

From (10) to (14), the characteristic of cepstrum can be summarized as follows: (1) the cepstrum calculating the inverse Fourier transform of the periodic components in frequency domain makes a high identification precision for multiple harmonics that may represent fault features; (2) the convolution product of the vibration source and transmission path in time domain is converted in addition to cepstrum domain, which can be separated easily; (3) the logarithm gives higher weights for weak amplitudes and lower weights for intensive amplitudes in frequency domain, which can evidence the incipient fault features in cepstrum domain; (4) inverse Fourier transform of the logarithm of multiple harmonics in frequency domain makes the cepstrum steady and robust, and it is insensitive to a change in load. Thus, cepstrum is suitable for quantizing the fault feature of bearing in DDWT.

4.3. Quantization Index of the Fault Feature. As shown in Figure 3, defects on bearing component usually generate multiple fault features. Correspondingly, the fault features should be emerged in cepstrum domain. Taking the roller defect in Figure 3(c), for example, RSF and FTF are fault feature frequencies in frequency domain, and they are transformed as corresponding spectral lines in cepstrum domain. Then, a cepstrum based bearing fault index for faulty DDWT can be calculated as

$$
C_{\mathrm{Q}}=\frac{\left(C_{\mathrm{FTF}}+C_{\mathrm{RSF}}\right)}{2},
$$




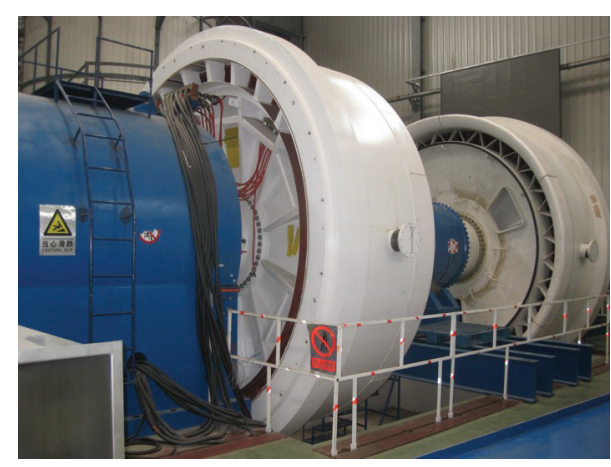

(a)

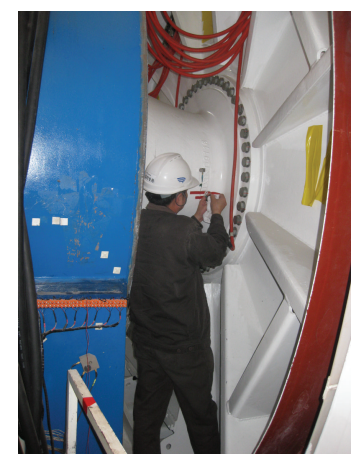

(b)

FIGURE 6: Test platform of direct drive wind turbine. (a) Platform and (b) transducer installation.

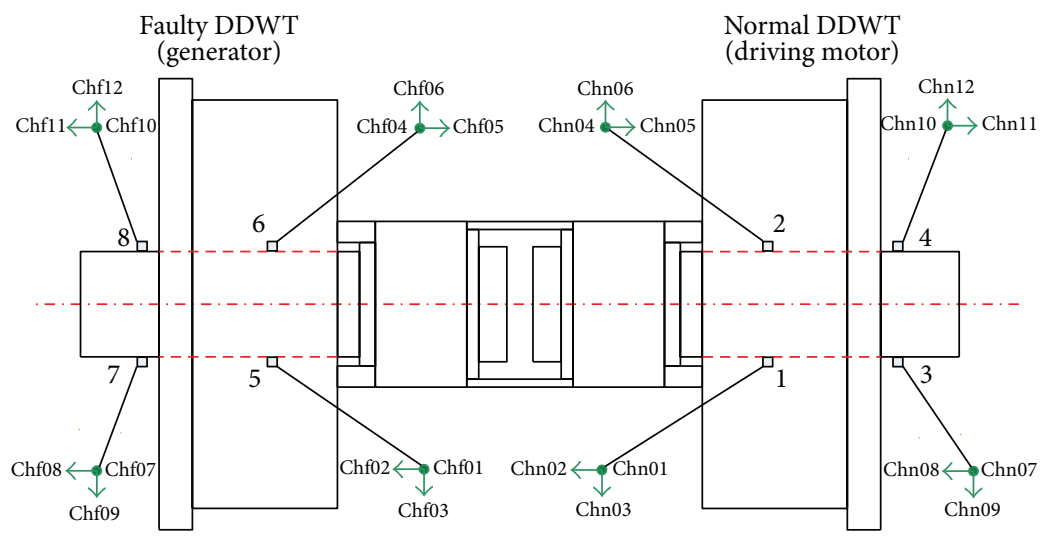

FIGURE 7: Placement of piezoelectric acceleration transducers.

where $C_{\mathrm{FTF}}$ and $C_{\mathrm{RSF}}$ denote the amplitudes corresponding to the FTF and RSF in cepstrum, respectively.

\section{Testing and Analysis}

5.1. Test Platform. The tested DDWT has been put into operation for about two years, and field technician found that its health condition was abnormal. In order to clarify the concrete fault in the DDWT, it was carried to test lab and connected with a normal DDWT to construct a full-scale test rig that is shown as in Figure 6(a). In this platform, the normal DDWT was used as driving motor and the faulty one was used as generator. Figure 6(b) shows the installation process of acceleration transducers. The rated power of the tested DDWT is $1.5 \mathrm{MW}$, the diameter of blades is 77 meters, the height of the rotor hub is 65 meters, and the rated rotational speed of the external rotor is $17.3 \mathrm{r} / \mathrm{min}$. The structures of the two tested DDWT are the same, which are shown in Figure 1.

Four triaxial accelerometers are installed in the tested faulty DDWT and the normal one, respectively, which is shown as in Figure 7. Therefore, there are 12 channels totally for each tested wind turbine. The acceleration transducers Kistler 8795 are adopted to monitor and diagnose bearing fault, and they are glued on the surface of the stationary main shaft. The piezoelectric effect based acceleration transducer
TABLE 1: 9 operation conditions and the fault feature frequencies.

\begin{tabular}{ccccccc}
\hline & $f_{r}(\mathrm{~Hz})$ & $P(\mathrm{~kW})$ & $\mathrm{RPFI}(\mathrm{Hz})$ & $\mathrm{RPFO}(\mathrm{Hz})$ & $\mathrm{RSF}(\mathrm{Hz})$ & $\mathrm{FTF}(\mathrm{Hz})$ \\
\hline C1 & 0.133 & 0 & 3.432 & 3.101 & 1.315 & 0.070 \\
C2 & 0.15 & 40 & 3.861 & 3.489 & 1.479 & 0.079 \\
C3 & 0.17 & 60 & 4.376 & 3.954 & 1.676 & 0.089 \\
C4 & 0.25 & 205 & 6.435 & 5.815 & 2.466 & 0.131 \\
C5 & 0.262 & 125 & 6.735 & 6.087 & 2.581 & 0.137 \\
C6 & 0.267 & 300 & 6.864 & 6.203 & 2.630 & 0.140 \\
C7 & 0.273 & 200 & 7.035 & 6.358 & 2.696 & 0.143 \\
C8 & 0.283 & 345 & 7.293 & 6.590 & 2.794 & 0.149 \\
C9 & 0.283 & 485 & 7.293 & 6.590 & 2.794 & 0.149 \\
\hline
\end{tabular}

has a dynamic response range from $1 \mathrm{~Hz}$ to $2000 \mathrm{~Hz}$ and a resonance frequency about $20 \mathrm{kHz}$, and its sensitivity is $100 \mathrm{mV} / \mathrm{g}$. The sampling frequency is $5000 \mathrm{~Hz}$.

Real wind turbine often operates under harsh condition of varying speed and alternating loads. Thus, the vibration test is performed considering nine different operational conditions shown as in Table 1. The corresponding fault feature frequencies of rear bearing in DDWT are also listed in Table 1 according to (1) and (2).

In Table 1, $f_{r}$ denotes the rotational frequency of the DDWT, and $P$ denotes the power at the same time. 

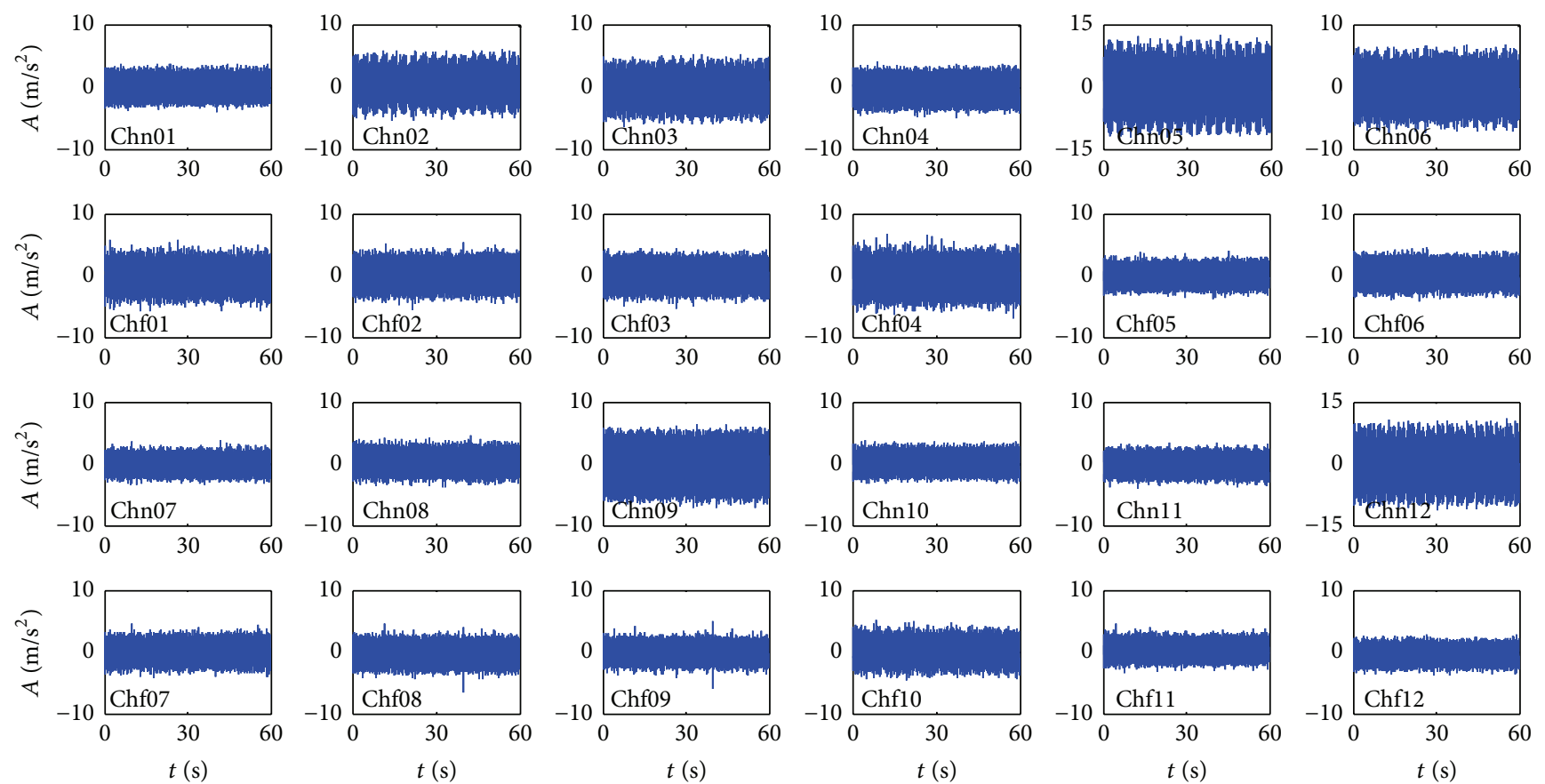

FIgURE 8: Time signals.

5.2. Fault Feature Extraction. Shown as in Table 1, the fault feature frequencies of rear bearing in DDWT are low, especially for FTF. Therefore, the vibration signals must be recorded for a long time to identify them. So the record time of vibration signals is more than $60 \mathrm{~s}$ for every test condition. Figure 8 shows the time signals of 24 channels at the condition C9. The first and the third rows represent the vibration signals from normal DDWT, while the second and the forth rows represent the vibration signals from the faulty one. Observing the 12 channels of the normal DDWT, the vibration amplitudes have obvious differences, especially in chn02, chn03, chn05, chn06, chn09, and chn12, which are more than other normal channels. Figure 9 shows the vibration signals in chn02, chn05, and chn12, where the periodic fluctuation $3.54 \mathrm{~s}$ is evidenced. $3.54 \mathrm{~s}$ represents the rotational period of DDWT, and it may show an eccentricity between rotor and stator because the DDWT is normal as a prior. On the contrary, the vibration amplitudes of the faulty DDWT in Figure 8 are relatively steady, which do not exceed $\pm 5 \mathrm{~m} / \mathrm{s}^{2}$. Just comparing the vibration amplitudes of the normal DDWT with the faulty one, we cannot find useful information representing bearing defect of the faulty DDWT.

Then, the vibration signals in chn08 and chf08 denoting axis-direction are analyzed in frequency domain, and the corresponding power spectra are shown as in Figure 10. Figure 10(a) represents the normal DDWT and Figure 10(b) represents the faulty one. There is distinct difference at the frequency range from $100 \mathrm{~Hz}$ to $200 \mathrm{~Hz}$ (enclosed by ellipse). Bearing fault may be buried in the enclosed frequency band.

So the signals in chn08 and chf08 are filtered by band-pass filter with the cut-off frequencies $100 \mathrm{~Hz}$ and $200 \mathrm{~Hz}$ and the envelope spectra are shown in Figure 11. In Figure 11(a), there are multiharmonic components of $f_{r}(0.283 \mathrm{~Hz})$ that denotes
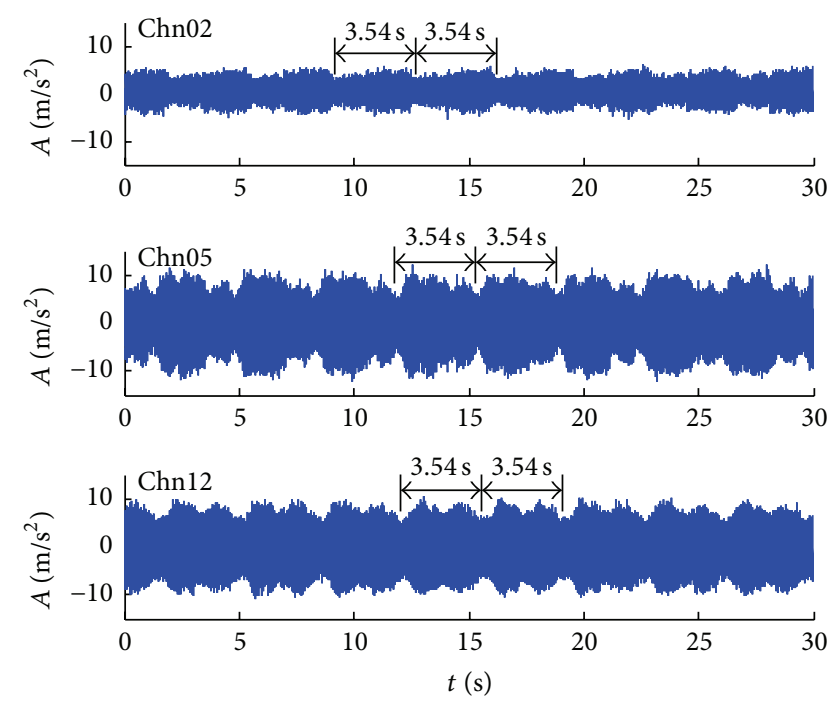

FIGURE 9: Time signals of three channels in normal DDWT.

the rotational frequency of external rotor, which accord with the periodic fluctuation in Figure 9. In Figure 11(b), besides the components of rotational frequency, $5.58 \mathrm{~Hz}$, the second harmonic of RSF emerges. Although all the features in Figure 11(b) are weak, they still present that there are possible defects on the rollers of the rear bearing. The fault of the roller elements is usually modulated by the feature of FTF, shown as in Figure 3(c); however, there are no FTF components in Figure 11(b).

Next, the vibration signals in chn08 and chf08 are processed based on complex Morlet wavelet transform. The 


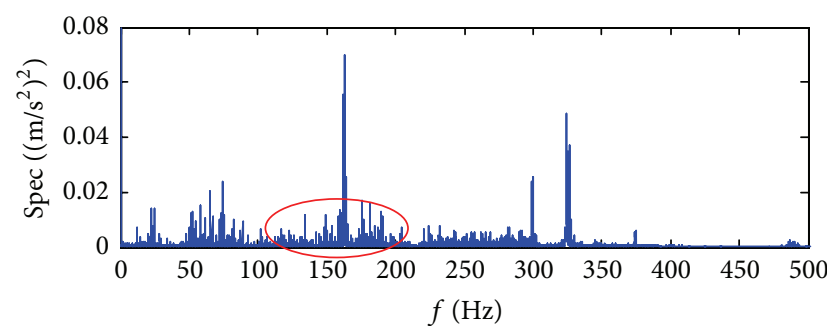

(a)

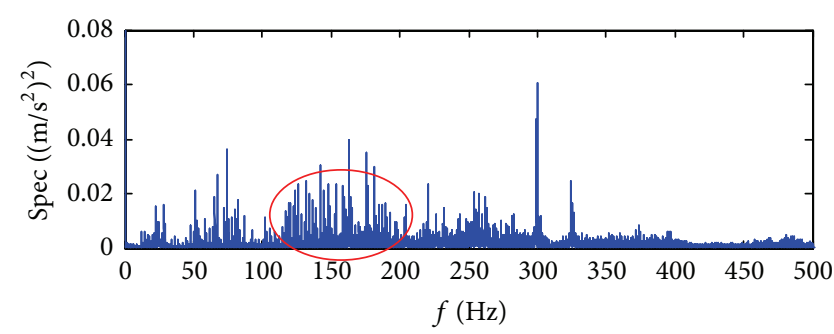

(b)

Figure 10: Amplitude spectra of vibration signals in chn08 and chf08. (a) Normal and (b) fault.

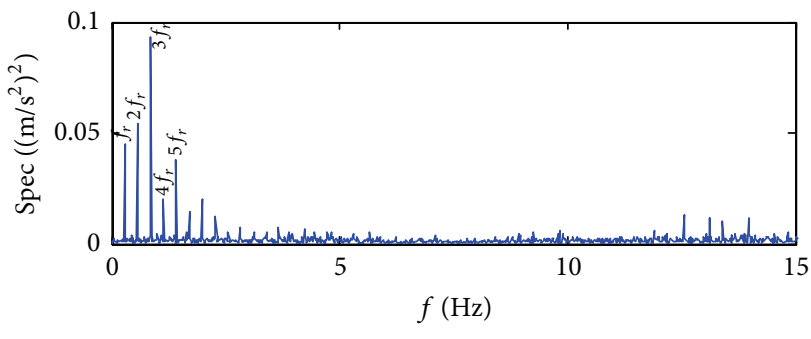

(a)

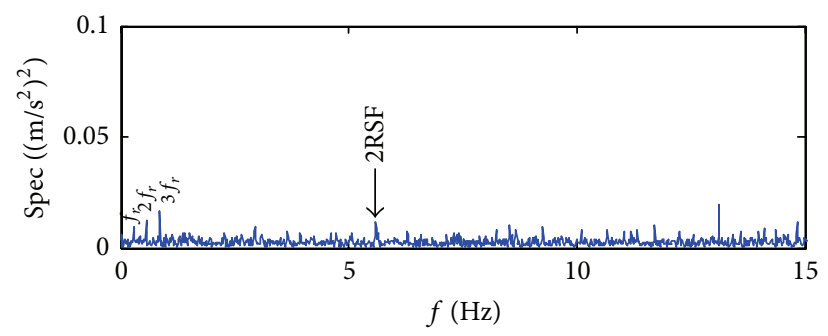

(b)

FIGURE 11: Envelope spectrum after band-pass filtering. (a) Normal and (b) fault.

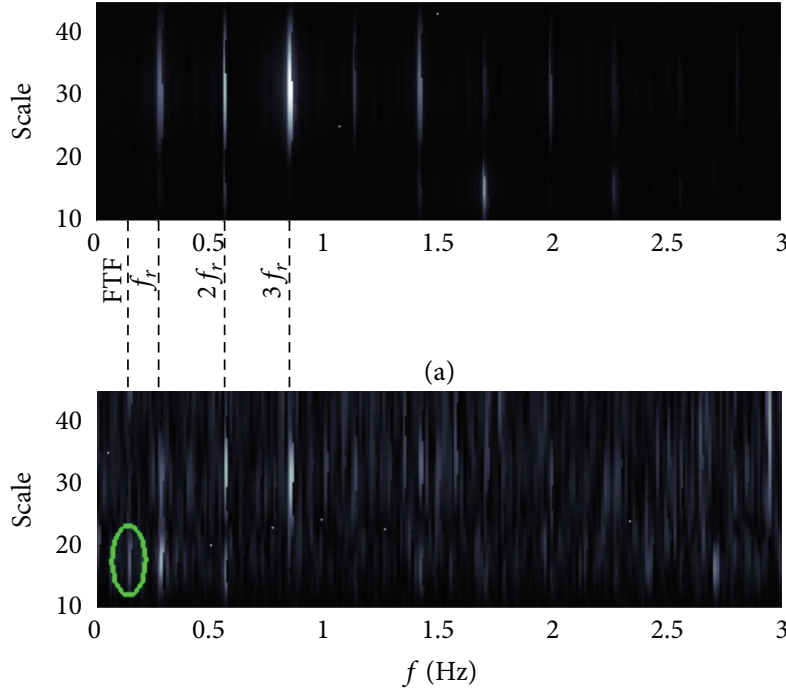

(b)

FIGURE 12: Multiscale enveloping spectrogram in chn08 and chf08. (a) Normal and (b) fault.

range of wavelet scale is from 10 to 45 and the step is 0.25 . According to (7) and (8), the corresponding MuSEnSs are shown as in Figures 12 and 13. In Figure 12(a), the rotational frequency and its harmonics are obvious, which accord with the demodulation results in Figure 11(a). In Figure 12(b), there emerges a frequency component of $0.15 \mathrm{~Hz}$, enclosed by the ellipse, which accords with the FTF at condition C9 in Table 1. Figure 13 shows the frequency range from 0 to $30 \mathrm{~Hz}$, and it manifests more fault information about RSF and FTF. There

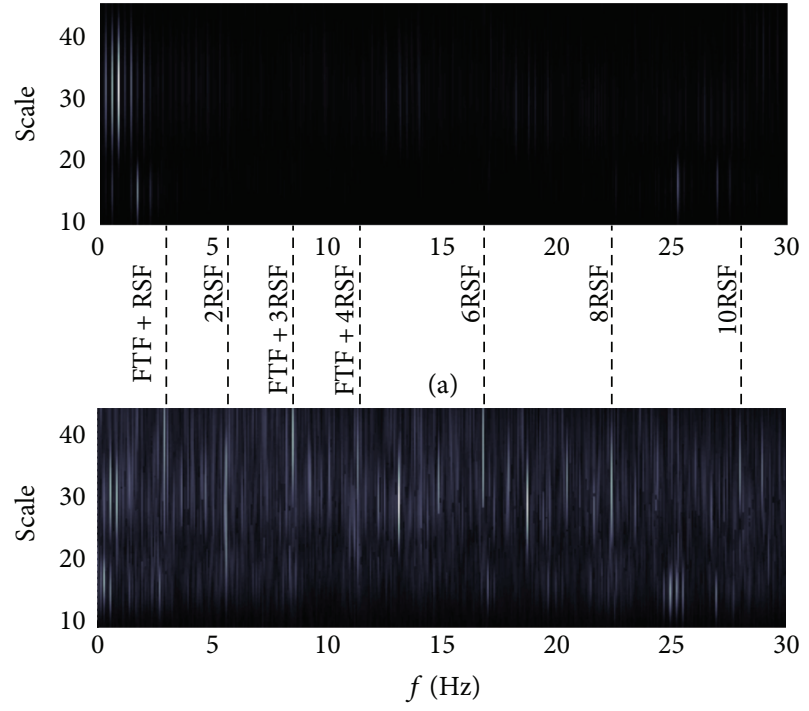

(b)

FIGURE 13: Multiscale enveloping spectrogram in chn08 and chf08. (a) Normal and (b) fault.

are frequency components of 2.94, 5.59, 8.54, 11.33, 16.77, 22.36, and $27.95 \mathrm{~Hz}$ in Figure 13(b), which represent the sum of FTF and RSF, two-time RSF, the sum of three-time RSF and FTF, and the sum of four-time RSF and FTF, the six-time RSF, the eight-time RSF, and the ten-time RSF, respectively. All the above information indicates there are defects on the roller in the rear bearing. Figures 14 and 15 are the slices of MuSEnSs of the normal and faulty DDWTs at scales 15 and 
TABLE 2: Detection results of FTF under different conditions and directions.

\begin{tabular}{ccccccccccccccc}
\hline & Chf01 & Chf02 & Chf03 & Chf04 & Chf05 & Chf06 & Chf07 & Chf08 & Chf09 & Chf10 & Chf11 & Chf12 \\
\hline C1 & $\times$ & $\times$ & $\times$ & $\times$ & $\times$ & $\times$ & $\times$ & $\times$ & & $\times$ & $\times$ & $\times$ & $\times$ \\
C2 & $\times$ & $\times$ & $\times$ & $\times$ & $\times$ & $\sqrt{ }$ & $\times$ & $\times$ & $\times$ & $\times$ & $\times$ & $\times$ \\
C3 & $\times$ & $\sqrt{ }$ & $\times$ & $\times$ & $\sqrt{ }$ & $\sqrt{ }$ & $\times$ & $\times$ & $\times$ & $\times$ & $\times$ & $\times$ \\
C4 & $\times$ & $\sqrt{ }$ & $\times$ & $\times$ & $\times$ & $\times$ & $\times$ & $\sqrt{ }$ & $\times$ & $\times$ & $\times$ & $\sqrt{ }$ \\
C5 & $\times$ & $\sqrt{ }$ & $\times$ & $\times$ & $\times$ & $\times$ & $\sqrt{ }$ & $\sqrt{ }$ & $\times$ & $\times$ & $\sqrt{ }$ & $\sqrt{ }$ \\
C6 & $\times$ & $\times$ & $\sqrt{ }$ & $\times$ & $\sqrt{ }$ & $\sqrt{ }$ & $\times$ & $\sqrt{ }$ & $\times$ & $\times$ & $\sqrt{ }$ & $\sqrt{ }$ \\
C7 & $\sqrt{ }$ & $\sqrt{ }$ & $\times$ & $\sqrt{ }$ & $\sqrt{ }$ & $\sqrt{ }$ & $\sqrt{ }$ & $\sqrt{ }$ & $\times$ & $\sqrt{ }$ & $\sqrt{ }$ & $\times$ \\
C8 & $\times$ & $\sqrt{ }$ & $\times$ & $\times$ & $\sqrt{ }$ & $\sqrt{ }$ & $\times$ & $\times$ & & $\times$ & $\times$ & $\sqrt{ }$ & $\sqrt{ }$ \\
C9 & $\times$ & $\sqrt{ }$ & $\times$ & $\sqrt{ }$ & $\sqrt{ }$ & $\times$ & $\times$ & $\sqrt{ }$ & $\times$ & $\times$ & $\sqrt{ }$ & $\times$ \\
\hline
\end{tabular}

$\times$ represents that FTF cannot be detected; $\sqrt{ }$ represents that FTF can be detected.

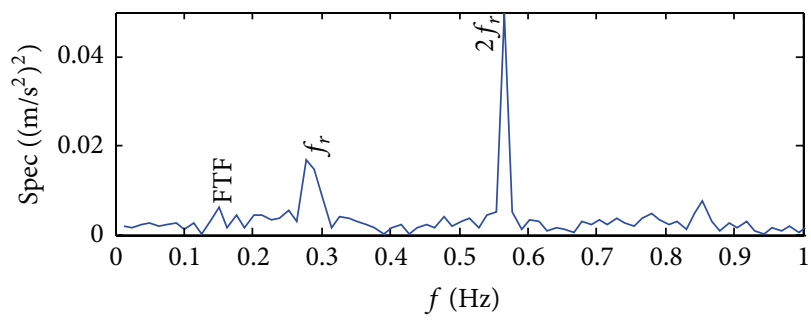

(a)

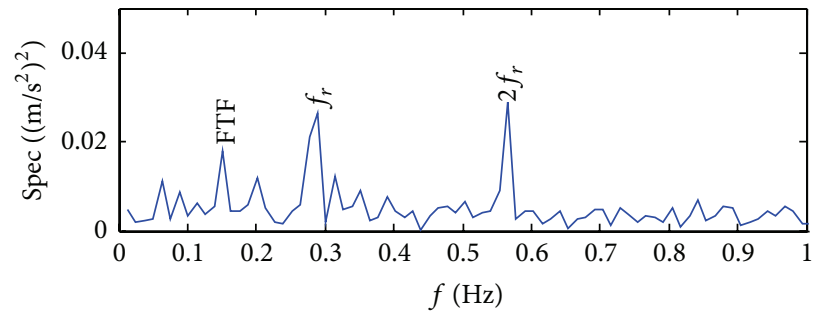

(b)

FIgUre 14: Slices of the MuSEnS at scale 15 in chn08 and chf08. (a) Normal and (b) fault.

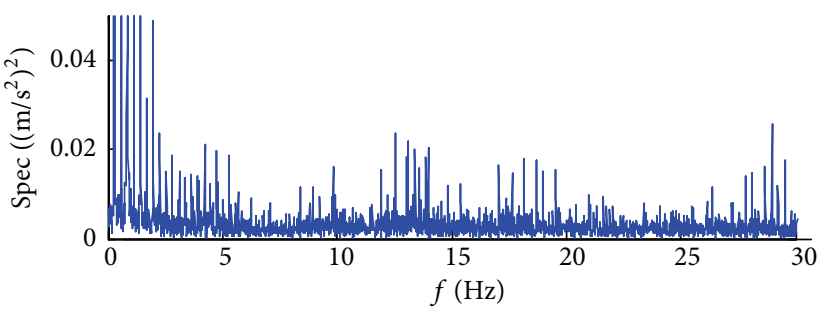

(a)

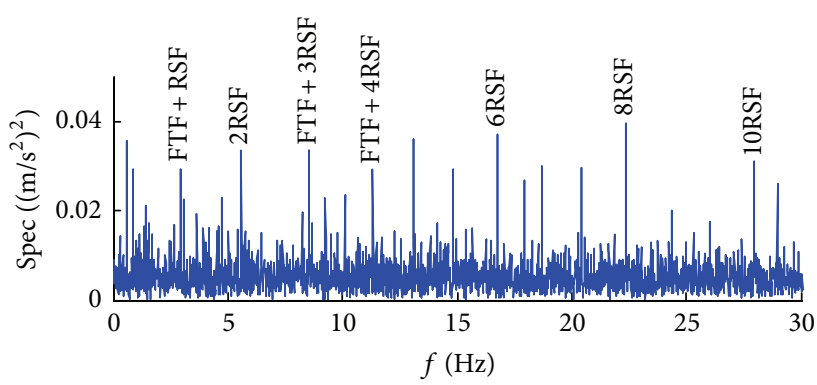

(b)

Figure 15: Slices of the MuSEnS at scale 35 in chn08 and chf08. (a) Normal and (b) fault.

35 , respectively, which show the fault frequency components of MuSEnS accurately.

From Figures 12 and 14, the weak feature of FTF can be detected distinctly. Further, all the operation conditions and test channels are considered to induce the defect position. The detection results about FTF of all 12 channels at 9 operation conditions are listed in Table 2. In $\mathrm{C} 1$ and $\mathrm{C} 2$, the FTF feature can hardly be detected because of the low rotational speed and load. In most cases from C2 to C9, FTF can be detected in chf02, chf05, chf08, and chf11, which denotes that the defect on roller is sensitive to the axis-direction vibration. The defect on roller is inferred on the position enclosed by circles in Figure 2.

5.3. Fault Feature Quantization. Suffering from varying speed and alternating loads from stochastic wind, it is a challengeable task to quantize fault feature of bearing in DDWT. The whole vibration signals in chn08 and chf08 are analyzed using cepstrum, and the results are shown in Figure 16. Figure 16(a) is the cepstrum of the normal DDWT, where $1 / f_{r}(3.53 \mathrm{~s})$ and its harmonics emerge, which are the reciprocal of $0.283 \mathrm{~Hz}$ representing the rotational frequency of the DDWT. In Figure 16(b), the cepstrum of faulty DDWT shows the components of $0.358 \mathrm{~s}$ and $6.717 \mathrm{~s}$ denoting the reciprocal of RSF and FTF, respectively. However, there are also 1/RSF and 1/FTF components in Figure 16(a), and the amplitudes are lower than those in Figure 16(b). The reason is that the two DDWTs are connected concentrically, and the vibration impact from defective part of the faulty DDWT can be transferred to the normal one.

The bulges corresponding to FTF and RSF in cepstrum are collected from all the operation conditions and test 


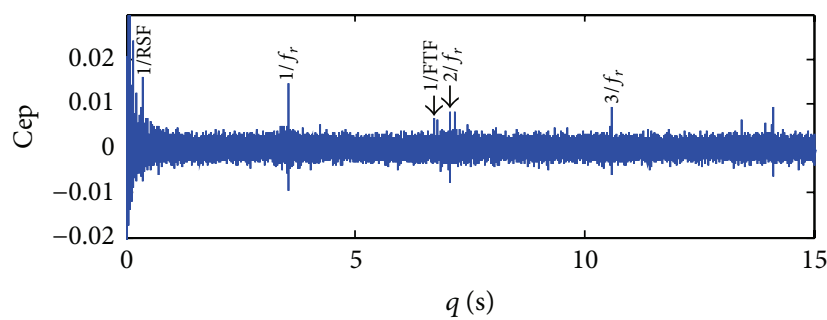

(a)

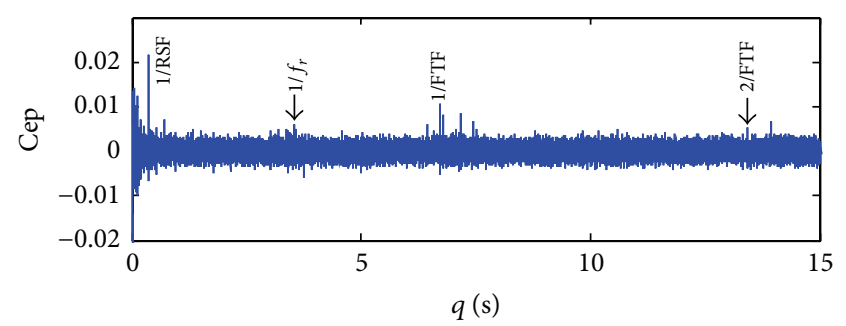

(b)

Figure 16: Cepstrum of vibration signals in chn08 and chf08. (a) Normal and (b) fault.

channels, and the fault index is calculated according to (15). There are total $12 \times 9=108$ test points. The fault indices of normal and faulty DDWT are shown in Figure 17, which fluctuate slightly following with different operational conditions. Taking the fault index in normal DDWT as reference, the quantization index of fault feature can be obtained through subtracting the fault index in normal DDWT from the one in faulty DDWT. The quantization index of fault feature is steady and is little affected by the varying rotational speed and loads, which is effective for long time condition monitoring for DDWT.

As a contrast, we extract the amplitude of two-time RSF based on enveloping demodulation in Figure 11 as the fault index, which is shown in Figure 18. The fault index using enveloping demodulation in faulty DDWT fluctuates acutely following with different operational conditions, while the fault index in normal DDWT is almost steady because there are no faults in the normal DDWT. Therefore, the quantization index based on enveloping demodulation is not suitable for long time condition monitoring for DDWT.

Most fault quantization indicators were derived as the ratio of extracted feature energy to total signal energy $[12,25$, 34 ] because the extracted feature energy was always a part of the original signal (reference value in denominator). In this case, we set the fault index in normal DDWT as reference value. As shown in Figure 18, the amplitude at enveloping frequency (modulation information) is sensitive to varying operation speeds and loads. Therefore, the ratio of fault index in faulty DDWT to the one in normal DDWT will fluctuate more fiercely than the difference in Figure 18. By comparison, the cepstrum based difference in Figure 17 between faulty DDWT and normal one is little sensitive to loads because it benefits from the two characteristics: (1) the logarithm gives higher weights for weak amplitudes and lower weights for intensive amplitudes in frequency domain, which can evidence the incipient fault features in cepstrum domain; (2) the integral calculation of all vibration amplitudes in frequency domain during inverse Fourier transform makes cepstrum steady and robust.

5.4. Discussion. Considering the concrete characteristic of direct drive wind turbine, to detect and quantize the bearing fault in DDWT, we should pay attention to the following instructions: (1) the record time of vibration signals must

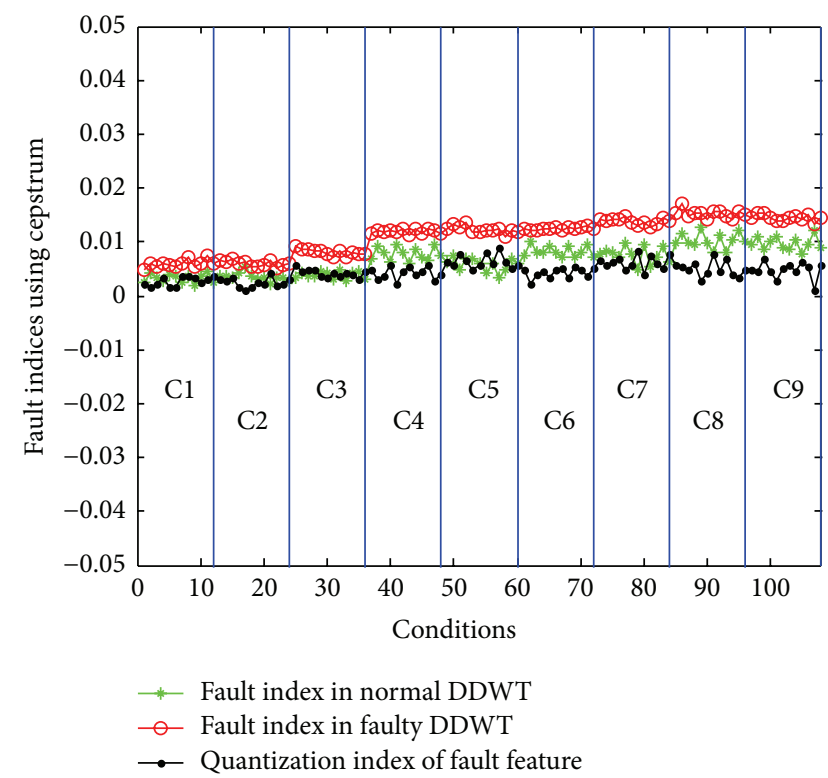

FIGURE 17: Fault indices using cepstrum analysis.

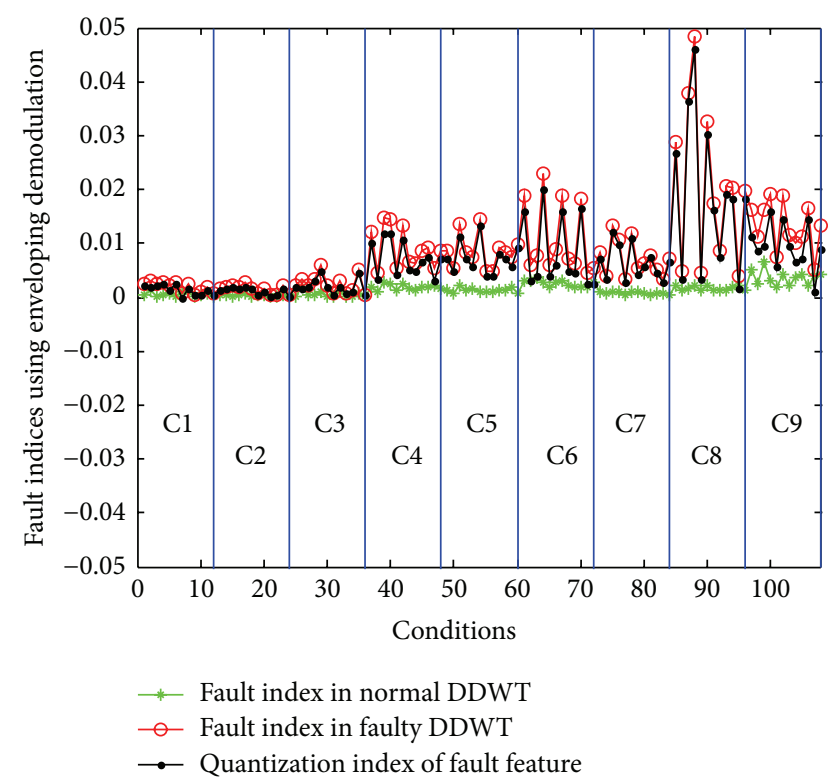

FIGURE 18: Fault indices using enveloping demodulation. 
be long enough to cover low fault feature frequencies of bearing; (2) the acceleration transducer should be installed in a correct direction, which can be used to detect defect position accurately; (3) the test under nine different operation conditions is performed within one day, and the degree of bearing fault is supposed to be steady and not deteriorate during the short time test; (4) although MuSEnS can detect bearing defect in most sensitive direction, it is incapable of FTF detection in other directions in most cases; (5) generally, the features of both FTF and RSF can arise in cepstrum of the faulty DDWT; however, they also cross into the normal DDWT due to the concentric connection.

\section{Conclusion}

It is significant to monitor and diagnose the fault of bearing that is a critical component in direct drive wind turbine. In this paper, a faulty DDWT and a normal one are connected concentrically to construct a test platform of comparative analysis. The MuSEnS that can decompose signal into different scales and provide multiscale enveloping information is applied to detect the FTF and RSF of rear bearing in the faulty DDWT. Based on the detection results, a cepstrum based fault index is proposed to quantize the fault feature of bearing, which can exclude the influence of operation condition and just reflect the degree of bearing defect. The presented application of MuSEnS and cepstrum is suitable for the condition monitoring and fault diagnosis of direct drive wind turbine.

\section{Competing Interests}

The authors declare that they have no competing interests.

\section{Acknowledgments}

The research presented in this paper was supported by National Natural Science Foundation of China (no. 51305135), Beijing Higher Education Young Elite Teacher Project (no. YETP0701), the Fundamental Research Funds for the Central Universities of China (no. 2015ZD15), and Science and Technology Plan Projects of Hebei (15214307D).

\section{References}

[1] International Energy Agency, IEA wind annual report for 2012, Country reports, http://www.ieawind.org/annual_reports _PDF/2012.html.

[2] International Energy Agency, IEA Wind Annual Report for 2013, Country Reports, International Energy Agency, 2013, http://www.ieawind.org/annual_reports_PDF/2013.html.

[3] J. Ribrant and L. M. Bertling, "Survey of failures in wind power systems with focus on Swedish wind power plants during 19972005," IEEE Transactions on Energy Conversion, vol. 22, no. 1, pp. 167-173, 2007.

[4] M. L. Wymore, J. E. Van Dam, H. Ceylan, and D. Qiao, "A survey of health monitoring systems for wind turbines," Renewable and Sustainable Energy Reviews, vol. 52, pp. 976-990, 2015.
[5] D. McMillan and G. W. Ault, "Techno-economic comparison of operational aspects for direct drive and gearbox-driven wind turbines," IEEE Transactions on Energy Conversion, vol. 25, no. 1, pp. 191-198, 2010.

[6] S. Li, T. A. Haskew, and L. Xu, "Conventional and novel control designs for direct driven PMSG wind turbines," Electric Power Systems Research, vol. 80, no. 3, pp. 328-338, 2010.

[7] P. D. McFadden and J. D. Smith, "Model for the vibration produced by a single point defect in a rolling element bearing," Journal of Sound and Vibration, vol. 96, no. 1, pp. 69-82, 1984.

[8] P. D. McFadden and J. D. Smith, "The vibration produced by multiple point defects in a rolling element bearing," Journal of Sound and Vibration, vol. 98, no. 2, pp. 263-273, 1985.

[9] N. Tandon and A. Choudhury, "A review of vibration and acoustic measurement methods for the detection of defects in rolling element bearings," Tribology International, vol. 32, no. 8, pp. 469-480, 1999.

[10] M. Feldman, "Hilbert transform in vibration analysis," Mechanical Systems and Signal Processing, vol. 25, no. 3, pp. 735-802, 2011.

[11] J. Antoni and R. B. Randall, “The spectral kurtosis: application to the vibratory surveillance and diagnostics of rotating machines," Mechanical Systems and Signal Processing, vol. 20, no. 2, pp. 308-331, 2006.

[12] R. Li, P. Sopon, and D. He, "Fault features extraction for bearing prognostics," Journal of Intelligent Manufacturing, vol. 23, no. 2, pp. 313-321, 2012.

[13] N. Sawalhi, R. B. Randall, and H. Endo, "The enhancement of fault detection and diagnosis in rolling element bearings using minimum entropy deconvolution combined with spectral kurtosis," Mechanical Systems and Signal Processing, vol. 21, no. 6, pp. 2616-2633, 2007.

[14] R. B. Randall, N. Sawalhi, and M. Coats, "A comparison of methods for separation of deterministic and random signals," The International Journal of Condition Monitoring, vol. 1, no. 1, pp. 11-19, 2011.

[15] P. Borghesani, P. Pennacchi, R. B. Randall, N. Sawalhi, and R. Ricci, "Application of cepstrum pre-whitening for the diagnosis of bearing faults under variable speed conditions," Mechanical Systems and Signal Processing, vol. 36, no. 2, pp. 370-384, 2013.

[16] J. Antoni, "Cyclic spectral analysis of rolling-element bearing signals: facts and fictions," Journal of Sound and Vibration, vol. 304, no. 3-5, pp. 497-529, 2007.

[17] V. K. Rai and A. R. Mohanty, "Bearing fault diagnosis using FFT of intrinsic mode functions in Hilbert-Huang transform," Mechanical Systems and Signal Processing, vol. 21, no. 6, pp. 2607-2615, 2007.

[18] R. B. Randall and J. Antoni, "Rolling element bearing diagnostics-a tutorial," Mechanical Systems and Signal Processing, vol. 25, no. 2, pp. 485-520, 2011.

[19] X. An, D. Jiang, S. Li, and M. Zhao, "Application of the ensemble empirical mode decomposition and Hilbert transform to pedestal looseness study of direct-drive wind turbine," Energy, vol. 36, no. 9, pp. 5508-5520, 2011.

[20] H. Polinder, F. Pijl, G. J. Vilder, and P. Tavner, "Comparison of direct-drive and geared generator concepts for wind turbines," in Proceedings of the IEEE International Conference on Electric Machines and Drives, pp. 543-550, San Antonio, Tex, USA, May 2005.

[21] F. Zhang and K. Ding, "Research on the three algorithms and limitations of generalized detection-filtering demodulation 
analysis," Journal of Vibration \& Shock, vol. 15, no. 2, pp. 243248, 2002.

[22] K. Ding and Z. G. Kong, "Modulation principle of amplitude \& frequency modulated signal and its demodulation procedure," Journal of Vibration \& Shock, vol. 24, no. 6, pp. 9-12, 2005.

[23] J. Antoni, "Cyclic spectral analysis in practice," Mechanical Systems and Signal Processing, vol. 21, no. 2, pp. 597-630, 2007.

[24] J. Antoni, "Cyclostationarity by examples," Mechanical Systems and Signal Processing, vol. 23, no. 4, pp. 987-1036, 2009.

[25] Z. P. Feng, M. J. Zuo, R. J. Hao, F. L. Chu, and M. El Badaoui, "Gear damage assessment based on cyclic spectral analysis," IEEE Transactions on Reliability, vol. 60, no. 1, pp. 21-32, 2011.

[26] R. Yan and R. X. Gao, "Multi-scale enveloping spectrogram for vibration analysis in bearing defect diagnosis," Tribology International, vol. 42, no. 2, pp. 293-302, 2009.

[27] J. Wang, R. X. Gao, and R. Yan, "Multi-scale enveloping order spectrogram for rotating machine health diagnosis," Mechanical Systems and Signal Processing, vol. 46, no. 1, pp. 28-44, 2014.

[28] B. P. Bogert, M. J. R. Healy, and J. W. Tukey, "The quefrency analysis of time series for echoes: cepstrum, pseudo-autocovariance, cross-cepstrum, and saphe cracking," in Proceedings of the Symposium on Time Series Analysis, pp. 209-243, John Wiley \& Sons, New York, NY, USA, 1963.

[29] D. G. Childers, D. P. Skinner, and R. C. Kemerait, "The cepstrum: a guide to processing," Proceedings of the IEEE, vol. 65, no. 10, pp. $1428-1443,1977$.

[30] R. B. Randall and N. Sawalhi, "A new method for separating discrete components from a signal," Sound and Vibration, vol. 45, no. 5, pp. 6-9, 2011.

[31] M. E. Badaoui, F. Guillet, and J. Danière, "New applications of the real cepstrum to gear signals, including definition of a robust fault indicator," Mechanical Systems and Signal Processing, vol. 18, no. 5, pp. 1031-1046, 2004.

[32] C.-S. Park, Y.-C. Choi, and Y.-H. Kim, "Early fault detection in automotive ball bearings using the minimum variance cepstrum," Mechanical Systems and Signal Processing, vol. 38, no. 2, pp. 534-548, 2013.

[33] S. Crutchfield, The Joy of Convolution, Johns Hopkins University, 2010.

[34] B. Zhang, T. Khawaja, R. Patrick, and G. Vachtsevanos, "Blind deconvolution denoising for helicopter vibration signals," IEEE/ASME Transactions on Mechatronics, vol. 13, no. 5, pp. 558-565, 2008. 


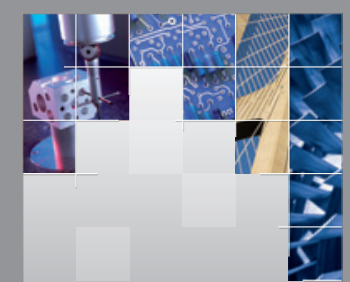

\section{Enfincering}
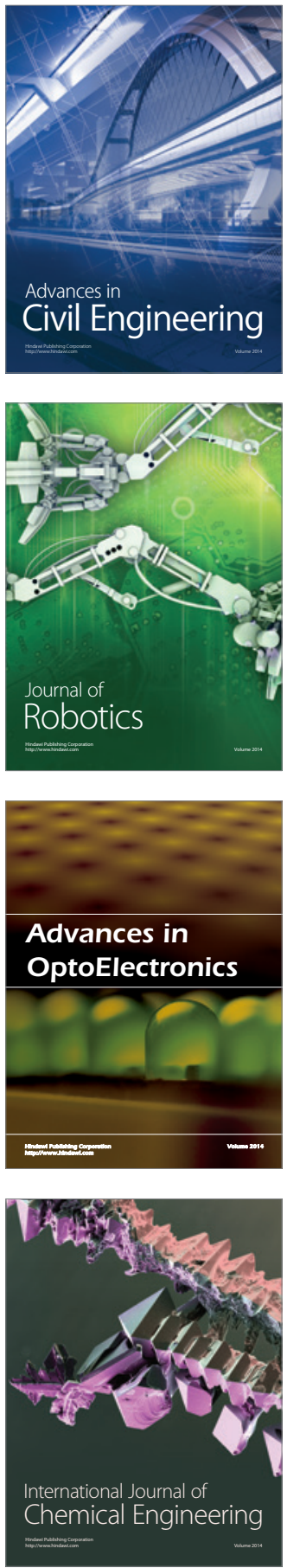

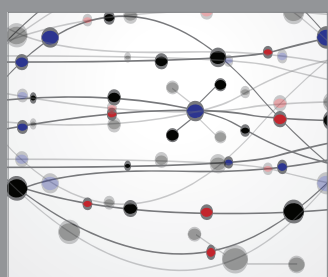

The Scientific World Journal

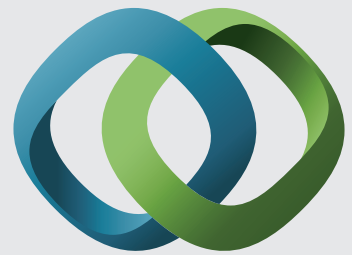

\section{Hindawi}

Submit your manuscripts at

http://www.hindawi.com
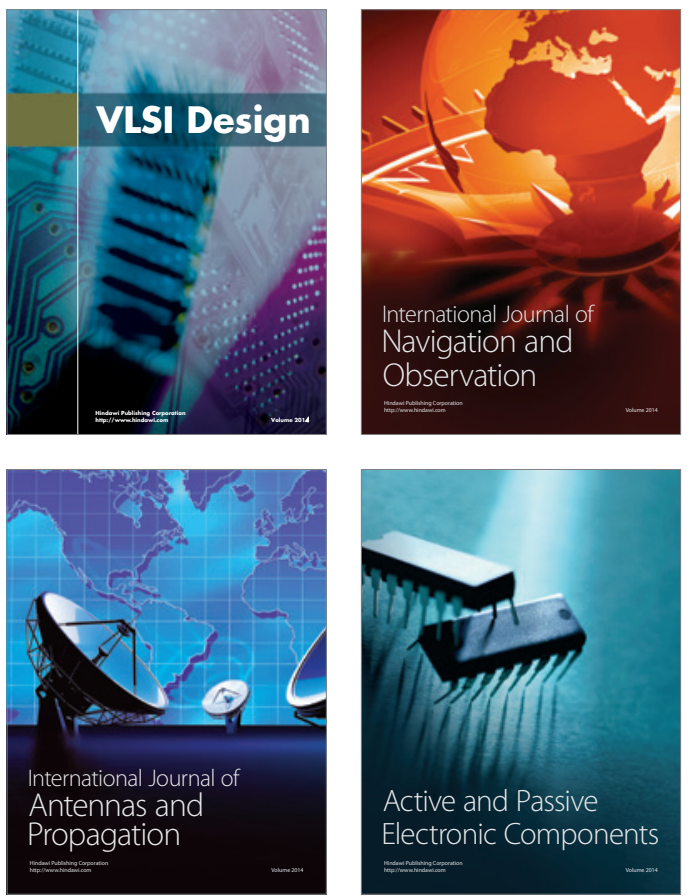
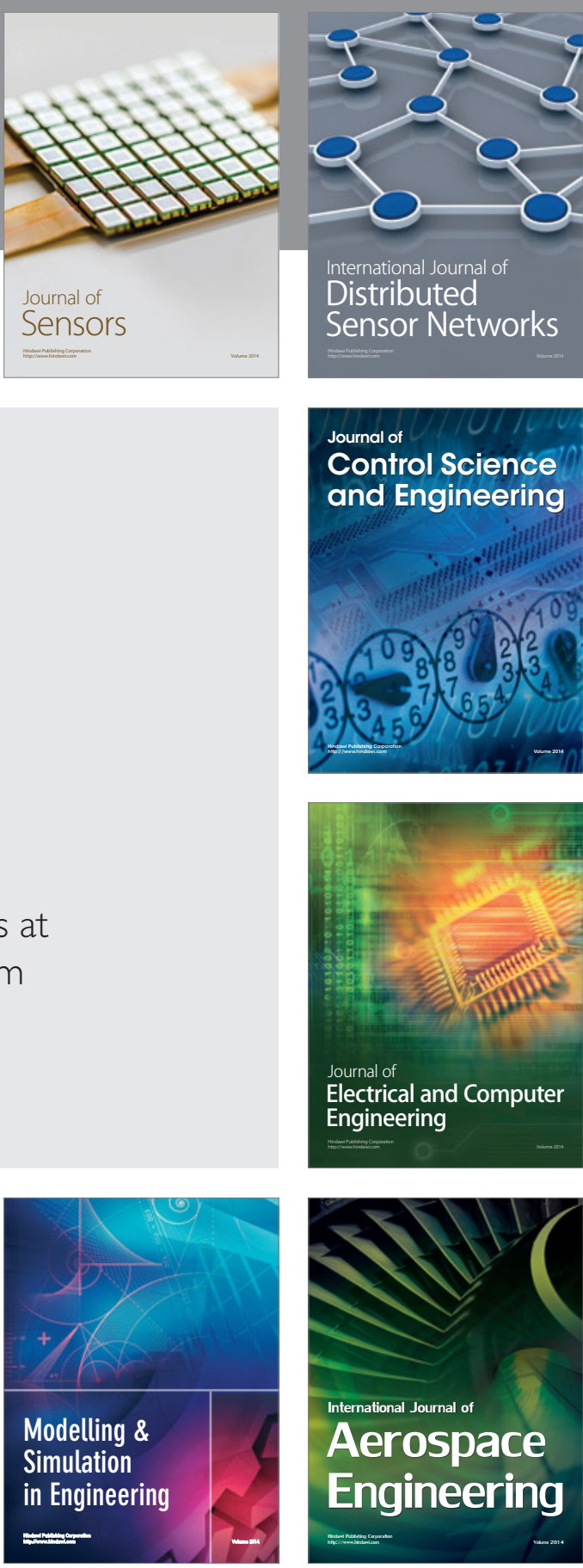

International Journal of

Distributed

Sensor Networks

Journal of

Control Science

and Engineering
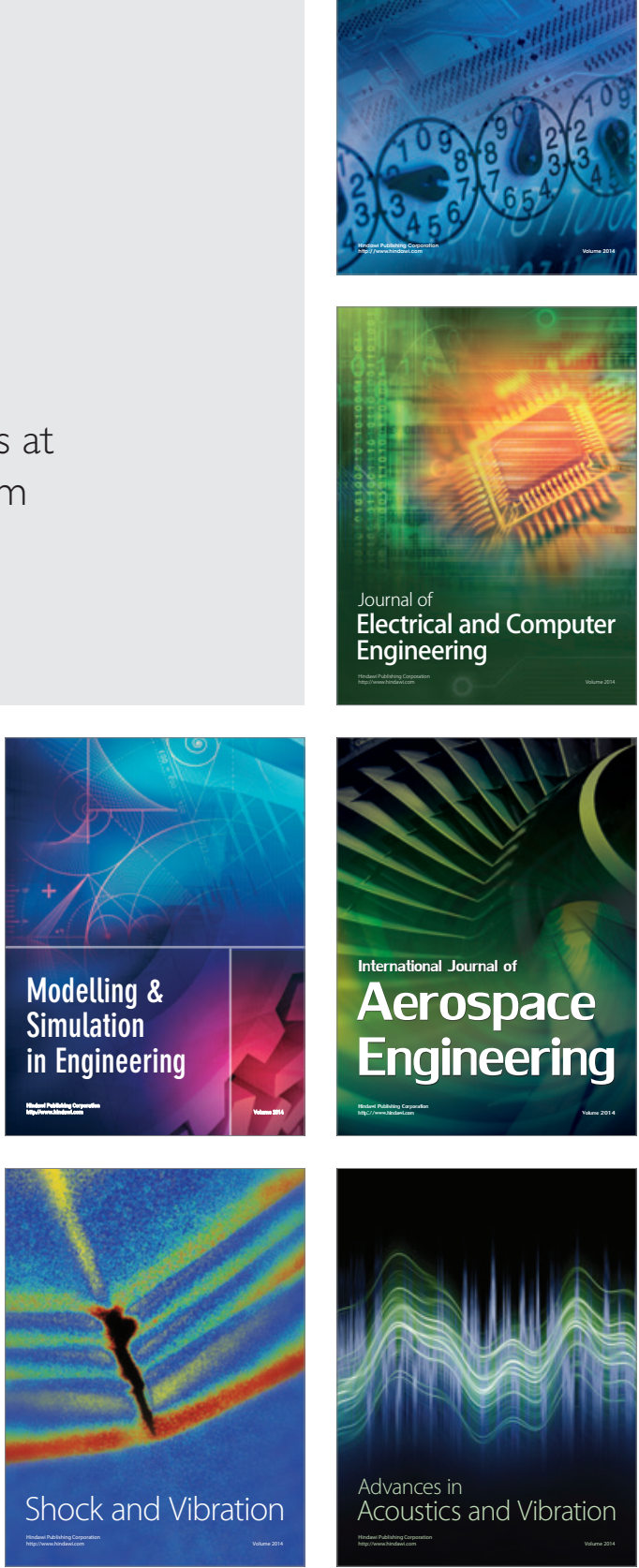